\title{
Bovine Staphylococcus aureus: Subtyping, evolution, and zoonotic transfer
}

\author{
R. Boss, ${ }^{\star}$ A. Cosandey, ${ }^{\star} †$ M. Luini,‡ K. Artursson,§ M. Bardiau,\# F. Breitenwieser,ll E. Hehenberger, $\dagger$

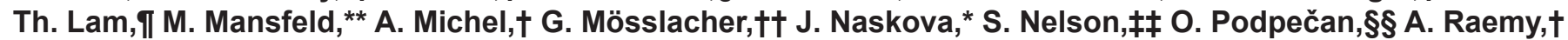 \\ E. Ryan,\#\# O. Salat,IIII P. Zangerl, ITा A. Steiner,† and H. U. Graber*1 \\ ${ }^{*}$ Agroscope, Institute for Food Sciences (IFS), Schwarzenburgstrasse 161, 3003 Berne, Switzerland \\ †Clinic for Ruminants, Department of Clinical Veterinary Medicine, Vetsuisse-Faculty, University of Berne, Bremgartenstrasse 109a, \\ P.O. Box 8466, 3001 Berne, Switzerland \\ łlstituto Zooprofilattico Sperimentale della Lombardia e dell'Emilia Romagna, Via Einstein, 26900 Lodi, Italy \\ §Department of Bacteriology, National Veterinary Institute, SE-751 89 Uppsala, Sweden \\ \#Bacteriology, Department of Infectious Diseases, Faculty of Veterinary Medicine, University of Liège, Avenue de Cureghem 6, 4000 Liège, \\ Belgium \\ IIMilchprüfring Baden-Württemberg e. V., Marie-Curie-Strasse 19, 73230 Kirchheim/Teck, Germany \\ TGD Animal Health, Arnsbergstraat 7, PO Box 9, 7400 AA Deventer, the Netherlands \\ ${ }^{* *}$ Carinthian Institute for Veterinary Disease Control, Kirchengasse 43, 9020 Klagenfurt, Austria \\ ††Animal Health Organisation Upper Austria, Bahnhofplatz 1, 4021 Linz, Austria \\ $\ddagger \ddagger$ Department of Production Animal Clinical Sciences, Norwegian School of Veterinary Science, Ullevalsvn 72, PO Box 8146 Dep, N-0033 Oslo, \\ Norway \\ §Ambulatory Clinic for Large Animals, University of Ljubljana, Veterinary Faculty, Gerbičeva ul. 60, 1000 Ljubljana, Slovenia \\ \#\#School of Veterinary Medicine, University College Dublin, Belfield, Dublin 4, Ireland \\ $\|I\|$ Veterinary Clinic of Haute Auvergne, Allauzier, 15100 Saint Flour, France \\ ПTाFederal Institute for Alpine Dairying BAM, 6200 Jenbach, Austria
}

\section{ABSTRACT}

Staphylococcus aureus is globally one of the most important pathogens causing contagious mastitis in cattle. Previous studies using ribosomal spacer (RS)PCR, however, demonstrated in Swiss cows that Staph. aureus isolated from bovine intramammary infections are genetically heterogeneous, with Staph. aureus genotype B (GTB) and GTC being the most prominent genotypes. Furthermore, Staph. aureus GTB was found to be contagious, whereas Staph. aureus GTC and all the remaining genotypes were involved in individual cow disease. In addition to RS-PCR, other methods for subtyping Staph. aureus are known, including spa typing and multilocus sequence typing (MLST). They are based on sequencing the spa and various housekeeping genes, respectively. The aim of the present study was to compare the 3 analytic methods using 456 strains of Staph. aureus isolated from milk of bovine intramammary infections and bulk tanks obtained from 12 European countries. Furthermore, the phylogeny of animal Staph. aureus was inferred and the zoonotic transfer of Staph. aureus between cattle and humans was studied. The analyzed strains could be grouped into 6 genotypic clusters, with CLB, CLC, and CLR being the most prominent ones. Comparing the 3 subtyping methods,

Received March 18, 2015.

Accepted August 27, 2015.

${ }^{1}$ Corresponding author: hansulrich.graber@agroscope.admin.ch
RS-PCR showed the highest resolution, followed by spa typing and MLST. We found associations among the methods but in many cases they were unsatisfactory except for CLB and CLC. Cluster CLB was positive for clonal complex (CC) 8 in $99 \%$ of the cases and typically positive for t2953; it is the cattle-adapted form of CC8. Cluster CLC was always positive for $\mathrm{t} 529$ and typically positive for CC705. For CLR and the remaining subtypes, links among the 3 methods were generally poor. Bovine Staph. aureus is highly clonal and a few clones predominate. Animal Staph. aureus always evolve from human strains, such that every human strain may be the ancestor of a novel animal-adapted strain. The zoonotic transfer of IMI- and milk-associated strains of Staph. aureus between cattle and humans seems to be very limited and different hosts are not considered as a source for mutual, spontaneous infections. Spillover events, however, may happen.

Key words: Staphylococcus aureus, bovine intramammary infection, subtyping, phylogeny, zoonotic transfer

\section{INTRODUCTION}

Staphylococcus aureus is known as an important pathogen responsible for contagious IMI in cattle worldwide (Sears and McCarthy, 2003). It is of central interest for the dairy industry and veterinary medicine in Switzerland, as it is responsible for massive economic loss in Switzerland (Heiniger et al., 2014). 
Intensive investigations were carried out in Switzerland in the last years to subtype Staph. aureus involved in bovine mastitis (Fournier et al., 2008; Graber et al., 2009). Fournier et al. (2008) developed a genotyping method based on amplifying the 16S-23S rRNA intergenic spacer region by PCR (ribosomal spacer-PCR, RS-PCR), which showed the associations of genotype with virulence gene pattern and clinical properties of the disease. In the first instance, 17 different genotypes were found and further characterized for their virulence gene patterns (Fournier et al., 2008). Staphylococcus aureus genotype B (GTB) and GTC were the most frequent genotypes found in bovine milk (80\%), but only GTB was contagious, with cow prevalences of up to $87 \%$ within herds, whereas GTC showed noncontagious behavior, infecting only single cows in a herd and single quarters of the udder (Fournier et al., 2008; Graber et al., 2009). Staphylococcus aureus GTB is characterized by the presence of the enterotoxin genes sea, sed, and $s e j$ and a SNP within the lukE gene (lukEB). In contrast, Staph. aureus GTC typically carries the enterotoxin genes sec, seg, sei, and tst (coding for toxic shock toxin-1) and is lukEB-negative (Fournier et al., 2008). All the other genotypes (GTOG) associated with Swiss mastitic dairy milk were rare, and their virulence gene patterns were inconsistent except that all were sea-negative (Fournier et al., 2008).

In humans, Staph. aureus is a well-known pathogen, responsible for wound infections and septicemia; it is, as a multiply resistant pathogen, an important and increasing problem in hospital environments and individual patients (Bannermann and Peacock, 2007). In terms of food safety, Staph. aureus is capable of producing a variety of enterotoxins that cause severe vomiting and diarrhea in humans (Hennekinne et al., 2012; Hummerjohann et al., 2014).

Staphylococcus aureus has been extensively studied and various typing methods have been described for subtyping this pathogen (Rabello et al., 2007; Hwang et al., 2010; van den Borne et al., 2010; Sakwinska et al., 2011). Two common methods are spa typing (Harmsen et al., 2003) and multilocus sequence typing (MLST; Enright et al., 2000). The former is based on DNA sequencing of the variable spacer region of the staphylococcal spa gene, whereas the latter requires the sequencing of 7 housekeeping genes. Other methods include pulsed-field gel electrophoresis (Bardiau et al., 2013; Lundberg et al., 2014) or binary typing (Zadoks et al., 2000). These analytic methods are useful to gain further insight into the pathogenesis of bovine mastitis caused by Staph. aureus but, because of their low throughput and high cost, they are less appropriate for large clinical investigations and routine analyses in veterinary medicine. Furthermore, the method is linked to the within-herd epidemiological and pathogenic properties of the different subtypes.

In the present study including 12 European countries, we compared the 3 analytic methods RS-PCR, spa typing, and MLST for subtyping 456 strains of Staph. aureus isolated from milk of bovine IMI and bulk tanks. Furthermore, we deciphered the phylogeny of animal Staph. aureus and studied the zoonotic transfer of Staph. aureus between cattle and humans.

\section{MATERIALS AND METHODS}

\section{Strains}

In total, 456 bovine strains of Staph. aureus originating from 12 European countries were examined (Table $1)$. They were reused from the companion study by Cosandey et al. (2016). The strains had been stored in skim milk at $-20^{\circ} \mathrm{C}$ and were recultured on blood agar (bioMérieux Suisse s.a., Geneva, Switzerland) by plating a loopful of bacteria on the agar and incubating it at $37^{\circ} \mathrm{C}$ for $24 \mathrm{~h}$. As described by Cosandey et al. (2016), the isolates had originated from aseptically collected milk samples from single quarters (SQM) with subclinical IMI, or from bulk tank milk (BTM) samples obtained according to the guidelines of the National Mastitis Council (NMC, 1999), or they had been taken from the authors' bacterial culture collections (BC). The BC strains had all been obtained from milk of cows with subclinical IMI using aseptic sample collection.

The BTM and SQM samples were selected from herds where IMI caused by Staph. aureus had been observed in the past year. The countries and regions delivering BTM and SQM samples are listed in Table 1. Among these countries, the cows of the herds to be sampled were selected according to different criteria including, at maximum, all lactating cows of a herd or, at minimum, the quarters positive by California Mastitis Test. Regardless of the selection criterion, however, SQM samples were collected aseptically. Cows with clinical mastitis and those under antimicrobial treatment were excluded. The SQM and BTM samples originated from 231 farms. The Swiss strains were taken from the authors' strain collection and included a random subset of Staph. aureus GTB $(\mathrm{n}=39)$ and GTC $(\mathrm{n}=32)$. For the other Swiss genotypes, all available strains of the strain collection were used $(\mathrm{n}=15)$.

Genotypes, spa types, sequence types, and clonal complexes (CC) were considered associated with IMI if the isolates had been obtained from aseptically taken milk samples as in the case the SQM pools or if they had been taken from the authors' strain collections (BC). An additional subset of 7 Swiss strains was used 
Table 1. European survey on Staphylococcus aureus in cow milk: participating countries and types of samples

\begin{tabular}{|c|c|c|c|}
\hline \multirow[b]{2}{*}{ Country (region) } & \multirow[b]{2}{*}{ Sample type ${ }^{1}$} & \multicolumn{2}{|c|}{$\begin{array}{l}\text { Total strains analyzed } \\
\text { per country (no.) }\end{array}$} \\
\hline & & IMI & Bulk tank milk \\
\hline Austria (Kärnten) & $\mathrm{BC}$ & 37 & \\
\hline Austria (Oberösterreich) & $\mathrm{BC}$ & 13 & \\
\hline Austria (Tirol) & $\mathrm{BC}^{2}$ & & 46 \\
\hline Belgium (Liège) & $\mathrm{BC}$ & 20 & \\
\hline France (Lozère) & SQM (8 herds) & 13 & \\
\hline \multirow[t]{2}{*}{ France (Rhône-Alpes) } & BTM & & 10 \\
\hline & SQM (2 herds) & 2 & \\
\hline Germany (Niedersachsen) & BTM & & 28 \\
\hline Germany (Baden-Württemberg) & BTM & & 39 \\
\hline \multirow{2}{*}{ Germany (Thüringen) } & BTM & & 28 \\
\hline & SQM (7 herds) & 5 & \\
\hline Ireland (Laighin) & SQM (10 herds) & 14 & 0 \\
\hline Italy (Lombardia) & $\mathrm{BC}$ & 24 & 0 \\
\hline Macedonia (Radoviš) & SQM (3 herds) & 3 & 0 \\
\hline \multirow[t]{2}{*}{ The Netherlands (Overijssel) } & $\mathrm{BC}$ & 14 & \\
\hline & BTM & & 25 \\
\hline Norway (Oslo) & SQM (21 herds) & 12 & 0 \\
\hline \multirow[t]{2}{*}{ Slovenia (Ljubljana) } & SQM (3 herds) & 5 & 0 \\
\hline & $\mathrm{BC}$ & 8 & \\
\hline Sweden & $\mathrm{BC}$ & 24 & 0 \\
\hline Switzerland & $\mathrm{BC}$ & 86 & 0 \\
\hline Total & & 280 & 176 \\
\hline
\end{tabular}

for phylogenetic analyses. All had been isolated from milk of Swiss cows with chronic subclinical mastitis and had been stored in skim milk at $-20^{\circ} \mathrm{C}$ until they were subjected to whole-genome sequencing (for more details see below).

\section{DNA Samples}

The DNA was extracted from single colonies of Staph. aureus. A colony was picked and resuspended in $100 \mu \mathrm{L}$ of $10 \mathrm{~m} M$ Tris- $\mathrm{HCl}$ and $10 \mathrm{~m} M$ EDTA ( $\mathrm{pH}=8.5$ ), incubated at $95^{\circ} \mathrm{C}$ for $10 \mathrm{~min}$, and immediately placed on ice. The lysates were diluted 1:100 in $\mathrm{H}_{2} \mathrm{O}$ to be used as templates for the different types of PCR (Table 2). The samples were stored at $-20^{\circ} \mathrm{C}$ and were analyzed within 2 weeks after extraction.

\section{Typing Methods}

Each of the following methods was evaluated using the 456 strains of Staph. aureus listed in Table 1.

$\boldsymbol{R} \boldsymbol{S}-\boldsymbol{P C R}$. For the present study, the genotyping results were from the companion paper (Cosandey et al., 2016), as identical strains were used for both studies. In brief, all strains were first analyzed by melting curve PCR for nuc as described by Syring et al. (2012). The nuc gene is highly specific for Staph. aureus (Brakstad et al., 1992; Graber et al., 2007) and was therefore used for definitive identification. All nuc-positive isolates (i.e., Staph. aureus) were then genotyped by RS-PCR using a miniaturized electrophoresis system (Agilent Technologies, Santa Clara, CA) as described by Fournier et al. (2008). New genotypes were subsequently named according to Fournier et al. (2008). Genotypic variants, differing in only 1 band from the genotype, were indicated with roman superscripts, as described in Cosandey et al. (2016).

spa Typing. The spa typing was performed according to Harmsen et al. (2003) using primers for PCR and sequencing as indicated in Table 2 . The method is based on the DNA sequence of the spacer region of the spa gene of Staph. aureus, which encodes for staphylococcal protein A. Amplification of the target was performed in a total volume of $25 \mu \mathrm{L}$ containing $300 \mathrm{n} M$ of each primer (Table 2), 12.5 $\mu \mathrm{L}$ of HotStarTaq Master Mix (Qiagen AG, Hombrechtikon, Switzerland), and 2.5 $\mu \mathrm{L}$ of template DNA. The reactions were run in a TProfessional thermal cycler (Biometra, Göttingen, Germany). Cycling included an initial denaturation step at $95^{\circ} \mathrm{C}$ for $15 \mathrm{~min}$ followed by 37 cycles of denaturation at $94^{\circ} \mathrm{C}$ for $60 \mathrm{~s}$, annealing at $60^{\circ} \mathrm{C}$ for $60 \mathrm{~s}$, and extension at $72^{\circ} \mathrm{C}$ for $60 \mathrm{~s}$. The PCR was terminated by a single extension step at $72^{\circ} \mathrm{C}$ for $10 \mathrm{~min}$. The PCR products were sent to a commercial sequencing center (Microsynth AG, Balgach, Switzerland) for cleaning-up and DNA sequencing. The obtained sequences were then 


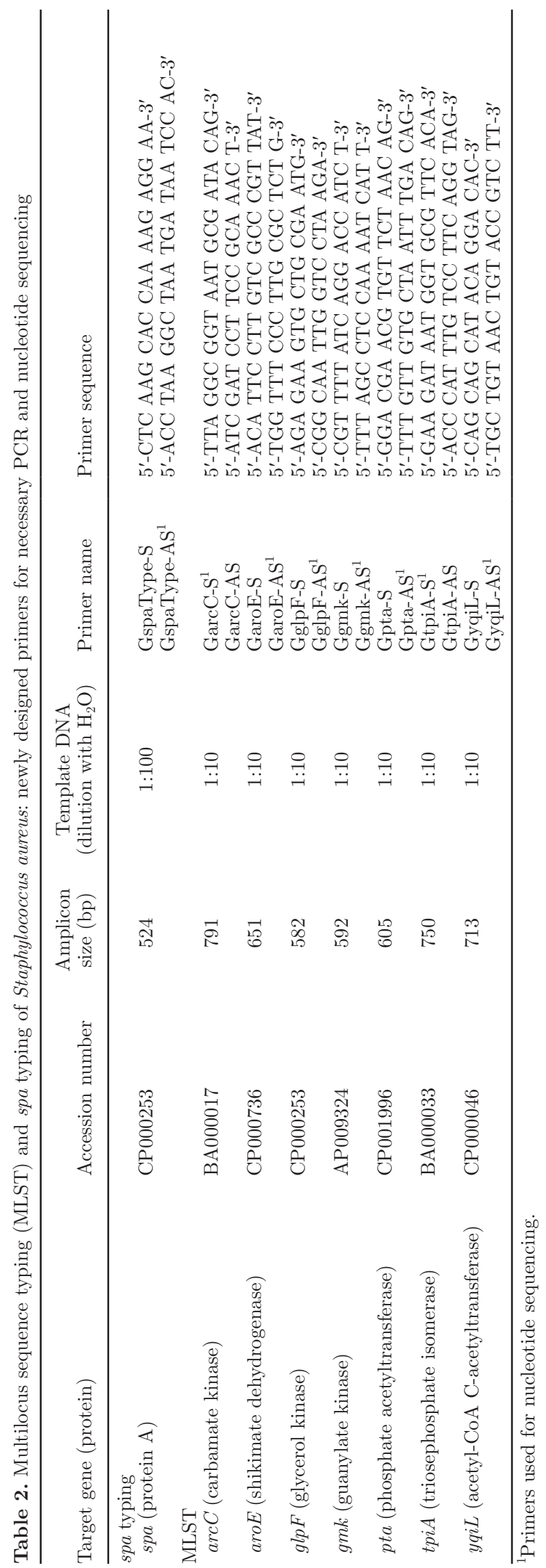

evaluated for the corresponding spa type (t) using the spa typing website (http://www.spaserver.ridom.de/; Harmsen et al., 2003).

MLST. Multilocus sequence typing is based on DNA sequencing of the 7 housekeeping genes arc $C$, aroE, glpF, gmk, pta, tpi, and yqiL, as described by Enright et al. (2000). In contrast to the original publication, new primer pairs for each gene were designed and used enabling unidirectional sequencing (Table 2). A standard PCR for each of the 7 housekeeping genes was performed. The reaction was run in a total volume of $25 \mu \mathrm{L}$ containing $300 \mathrm{n} M$ of each primer, $12.5 \mu \mathrm{L}$ of HotStarTaq Master Mix, and 2.5 $\mu \mathrm{L}$ of template DNA. Thermal cycling conditions consisted of an initial denaturation step at $95^{\circ} \mathrm{C}$ for 15 min followed by 35 cycles of denaturation at $94^{\circ} \mathrm{C}$ for $60 \mathrm{~s}$, annealing at $58^{\circ} \mathrm{C}$ for $60 \mathrm{~s}$ (except gmk: $53^{\circ} \mathrm{C}$ ), and extension at $72^{\circ} \mathrm{C}$ for $60 \mathrm{~s}$, followed by a final extension step at $72^{\circ} \mathrm{C}$ for $10 \mathrm{~min}$. The reactions were run in a $\mathrm{T}$ Professional thermal cycler (Biometra). The PCR products were then purified and sequenced by Microsynth. For each strain, the obtained chromatograms were then checked for their quality using the Chromas 2.4.2 software (www.softpedia.com). The quality-tested sequences were then evaluated by software tools of the MLST database (www.saureus. mlst.net), resulting in an allelic profile or sequence type (ST), which was then used together with the eBURST V3 program (www.eburst.mlst.net) to assign the CC to each strain.

Bovine strains positive for the corresponding genes were used as positive controls for all PCR assays; $\mathrm{H}_{2} \mathrm{O}$ served as a no-template control.

\section{Phylogenetic Analyses}

Phylogeny of animal and human strains of Staph. aureus was assessed, using the strains listed in Table 3. For this reason, whole-genome sequences of strains were obtained from the GenBank database (Benson et al., 2014) or the genomes of Swiss bovine strains with known genotypes $(\mathrm{n}=7)$ were fully sequenced. After thawing at $37^{\circ} \mathrm{C}$ for $10 \mathrm{~min}$, an aliquot of each strain was plated and grown on blood agar (bioMérieux Suisse s.a.). The strains on blood agar were then sent to Microsynth, where DNA extraction, library preparation, and whole-genome sequencing using the 454 technology (Roche, Basel, Switzerland) were performed. The obtained reads were assembled to contigs by Microsynth using the Newbler 2.6 software (Roche).

Phylogenetic analyses were performed as described by Kuhn et al. (2006). In particular, for each strain, the sequences of the 6 core adhesion genes clfA (clumping factor A), clfB (clumping factor B), fnbA (fibrinogen binding protein A), map (MHC class II analog protein), 
$s d r C$ (serine-aspartate repeat-containing protein $\mathrm{C}$ ), and spa (protein A) were concatenated. The concatenations were then aligned using the Needleman-Wunsch algorithm for optimal global alignment (Durbin et al., 2001) implemented in the Clone Manager 9.3 software (Scientific and Educational Software, Morrisville, NC). Maximum parsimony trees were then computed by the MEGA 6.06 software (Tamura et al., 2013) together with a cutoff for site coverage of $80 \%$. The statistical significance of branches was inferred by performing bootstrap analyses with 500 repetitions. Bootstrap values $\geq 80 \%$ were considered significant (Hillis and Bull, 1993; Felsenstein, 2004).

\section{Statistical Analysis}

Data are expressed as absolute numbers or percentage. Overview comparisons among genotypes, spa types, $\mathrm{ST}$, and $\mathrm{CC}$ were performed using $\mathrm{r} \times \mathrm{c}$ contingency tables. Specific comparisons were computed using $2 \times$ 2 contingency tables. For these analyses, exact tests were applied as implemented in the Systat 13 software package (Systat Software Inc., Richmond, CA). These tests count all possible outcomes exactly and allow, in contrast to classical chi-squared statistics, fitted cells that are sparse or even zero. A special case of these tests is Fisher's exact test for $2 \times 2$ contingency tables. A value of $P<0.05$ was considered significant. In case of multiple comparisons, $P$-values were adjusted according to Holm (1979).

For comparing the typing methods RS-PCR, spa typing, and MLST (ST and CC), the Simpson diversity index (SDI) was applied (Simpson, 1949). The SDI is a quantitative measure that reflects how many different types there are in a data set. In the case of RS-PCR, all different genotypes together with their variants were included, whereas for spa typing and MLST, the observed spa, ST, and CC types were used.

\section{RESULTS}

In this study, 456 strains isolated from bovine milk (Table 1) were analyzed by genotyping (RS-PCR), spa typing, and MLST. If a genotype with its variants comprised $\geq 20$ strains, they were combined in a genotypic cluster (CL). For example, all GTB and its variants were clustered in CLB. In total, 6 clusters were generated: CLB, CLC, CLF, CLI, CLR, and CLOT. Clusters CLB, CLC, and CLR were the largest, with 80 CLB strains (18\%), 115 CLC strains (25\%), and 96 CLR

Table 3. Strains of Staphylococcus aureus used for phylogenetic analyses ${ }^{1}$

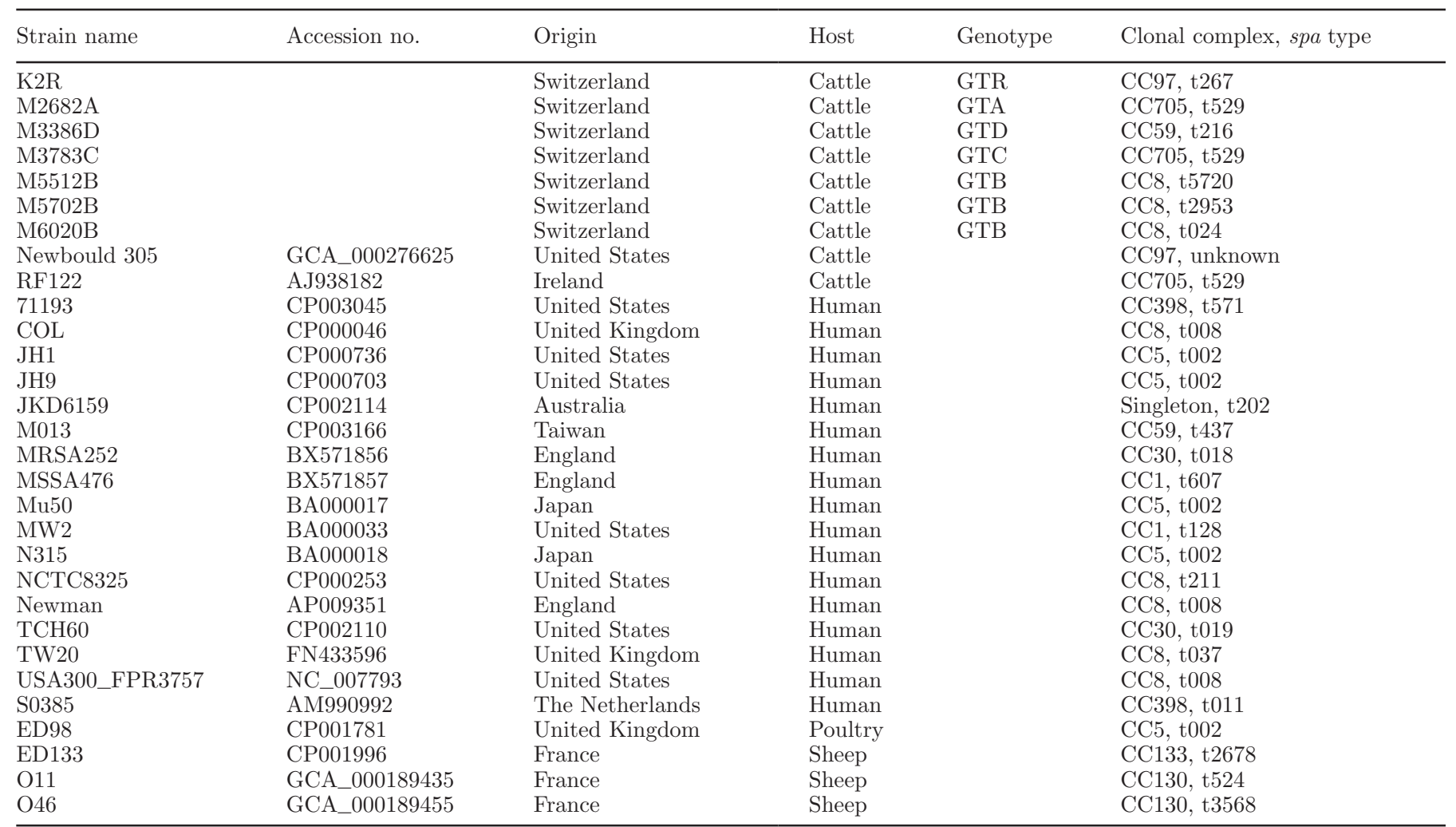

${ }^{1}$ For all these strains, the whole-genome sequences were available. Except for the Swiss strains, which had all been sequenced during the course of the present study, the sequences were downloaded from the GenBank database using the indicated accession numbers. 
Table 4. Distribution of spa types (t), sequence types (MLST_ST), and clonal complexes (MLST_CC) among the genotypic clusters CLB, CLC, CLF, CLI, and CLR of Staphylococcus aureus found in bovine milk samples from 12 European countries

\begin{tabular}{|c|c|c|c|c|c|c|}
\hline $\begin{array}{l}\text { Genotypic } \\
\text { cluster }\end{array}$ & $\begin{array}{c}\text { IMI } \\
{[\mathrm{BTM}]^{1}}\end{array}$ & spa type & $\begin{array}{c}\text { IMI } \\
{[\mathrm{BTM}]}\end{array}$ & MLST_ST & $\begin{array}{c}\text { IMI } \\
{[\mathrm{BTM}]}\end{array}$ & MLST_CC \\
\hline CLB & $\begin{array}{r}43[3] \\
12[5] \\
3[0] \\
2[0] \\
1[1] \\
3[0] \\
0[3] \\
4[0]\end{array}$ & $\begin{array}{l}\text { t2953 } \\
\text { t024 } \\
\text { t5270 } \\
\text { t008 } \\
\text { t5268 } \\
\text { t711, t5160, t11026 } \\
\text { t648, t6612, t6665 } \\
\text { Unknown }\end{array}$ & $\begin{array}{r}58[8] \\
2[0] \\
0[1] \\
8[3]\end{array}$ & $\begin{array}{l}\text { ST8 } \\
\text { ST433, ST631 } \\
\text { ST1498 } \\
\text { Unknown }\end{array}$ & $\begin{array}{c}67[12] \\
1[0]\end{array}$ & $\begin{array}{l}\text { CC8 } \\
\text { CC30 }\end{array}$ \\
\hline Total & 80 & & 80 & & 80 & \\
\hline CLC & 78 [37] & t529 & $\begin{aligned} 56 & {[24] } \\
7 & {[7] } \\
3 & {[0] } \\
0 & {[2] } \\
12 & {[4] }\end{aligned}$ & $\begin{array}{l}\text { ST504 } \\
\text { ST151 } \\
\text { ST479, ST1074, ST1380 } \\
\text { ST1123, ST1651 } \\
\text { Unknown }\end{array}$ & $\begin{array}{r}66[34] \\
2[1] \\
10[2]\end{array}$ & $\begin{array}{l}\text { CC705 } \\
\text { CC479 } \\
\text { Singleton }\end{array}$ \\
\hline Total & 115 & & 115 & & 115 & \\
\hline Total & 31 & & 31 & & 31 & \\
\hline CLI & $\begin{array}{r}10[2] \\
0[2] \\
2[0] \\
0[7]\end{array}$ & $\begin{array}{l}\text { t524 } \\
\text { t1965 } \\
\text { t005, negative } \\
\text { t078, t081, t257, t267, t359, t5180, } \\
\text { t9184 }\end{array}$ & $\begin{array}{l}6[2] \\
1[3] \\
0[2] \\
1[0]\end{array}$ & $\begin{array}{l}\text { ST71 } \\
\text { ST97 } \\
\text { ST8 } \\
\text { ST22 }\end{array}$ & $\begin{array}{l}5[6] \\
6[2] \\
0[2] \\
1[0]\end{array}$ & $\begin{array}{l}\text { CC97 } \\
\text { CC71 } \\
\text { CC8 } \\
\text { CC22 }\end{array}$ \\
\hline & & & $\begin{array}{l}0[1] \\
4[3]\end{array}$ & $\begin{array}{l}\text { ST25 } \\
\text { Unknown }\end{array}$ & $0[1]$ & $\mathrm{CC} 25$ \\
\hline Total & 23 & & 23 & & 23 & \\
\hline CLR & $\begin{array}{r}10[15] \\
11[2] \\
8[3] \\
1[9] \\
1[5] \\
1[3] \\
1[2] \\
0[3] \\
1[1] \\
4[0] \\
0[7]\end{array}$ & $\begin{array}{l}\text { t1403 } \\
\text { t524 } \\
\text { t267 } \\
\text { t224 } \\
\text { t359 } \\
\text { t521 } \\
\text { t3380 } \\
\text { t } 433 \\
\text { t527 } \\
\text { t376, t1166, t2678, t3495 } \\
\text { t044, t056, t1236, t2112, t4704, } \\
\text { t5693, t6367 } \\
\text { Unknown }\end{array}$ & $\begin{array}{l}7[13] \\
4[13] \\
8[1] \\
1[7] \\
3[0] \\
1[0] \\
0[4] \\
20[14]\end{array}$ & $\begin{array}{l}\text { ST97 } \\
\text { ST133 } \\
\text { ST71 } \\
\text { ST124 } \\
\text { ST352 } \\
\text { ST1119 } \\
\text { ST101, ST321, ST335, ST352 } \\
\text { Unknown }\end{array}$ & $\begin{array}{c}17[27] \\
10[15] \\
10[1] \\
0[2] \\
1[0] \\
0[2] \\
4[2] \\
2[3]\end{array}$ & $\begin{array}{l}\text { CC97 } \\
\text { CC133 } \\
\text { CC71 } \\
\text { CC30 } \\
\text { CC49 } \\
\text { CC9, CC101 } \\
\text { Singleton } \\
\text { Unknown }\end{array}$ \\
\hline Total & $\begin{array}{c}0[2] \\
96\end{array}$ & & 96 & & 96 & \\
\hline
\end{tabular}

${ }^{1} \mathrm{IMI}=$ the analyzed strains were all associated with bovine subclinical IMI and had been isolated from aseptically collected milk samples or had been taken from the authors' bacterial culture collections; BTM = the isolates were obtained from bovine bulk tank milk.

(21\%) strains, whereas CLF and CLI comprised 7 and $5 \%$ of the strains, respectively. All remaining genotypes and their variants $(\mathrm{n}=41)$ were clustered to CLOT (Table 4), which represented $24 \%$ of the total strains.

$\boldsymbol{C L} \boldsymbol{B}$. The CLB strains $(\mathrm{n}=80)$ could be attributed to 11 different spa types. The most frequent types were t2953 and t024 (Table 4), contributing 58 and $21 \%$ of the types, respectively. They were exclusively (t024) or almost exclusively (t2953) associated with CLB (for both types, $P<0.001$ ). With 1 to 3 strains, the remaining spa types were infrequently observed (Table 4). Overall, $83 \%$ of the strains were ST8 positive, whereas
$14 \%$ showed allelic profiles that were not present in the database (i.e., unknown). The remaining strains were positive for ST433, ST631, and ST1498, respectively. All strains except for one (CC30) belonged to CC8; ST8 and CC8 were both highly related to CLB $(P<$ 0.001 for both).

$\boldsymbol{C L} \boldsymbol{C}$. This cluster was the largest and it included 115 strains. All of these strains (100\%) showed the same spa type, t529, and showed, therefore, perfect association with CLC $(P<0.001)$. Cluster CLC was mainly associated with ST504 (70\%; $P<0.001)$ and ST151 $(12 \% ; P$ $<0.001)$. For $14 \%$ of the CLC strains, the ST remained 
unknown, whereas other types were found in $4 \%$ (Table 4). In total, $87 \%$ belonged to CC705 $(P<0.001), 10 \%$ were singletons, and $3 \%$ belonged to CC479 (Table 4).

$\boldsymbol{C L} \boldsymbol{R}$. Various spa types were observed (Table 4) in this cluster $(\mathrm{n}=96)$. The most recurrent were $\mathrm{t} 1403$ $(26 \% ; P<0.001)$, t524 (14\%; $P<0.001)$, and $\mathrm{t} 267$ $(11 \% ; P<0.001)$. Cluster CLR was associated with 11 different ST whereby ST97 (21\%; $P<0.001)$, ST133 $(18 \% ; P<0.001)$, and the unknown ST (35\%) were most prominent. These ST resulted in 7 different CC. With 46, 26, and $11 \%$ of strains, respectively, CC97, CC133, and CC71 were the largest complexes. The genotypic variants $\mathrm{R}, \mathrm{R}^{\mathrm{I}}$, and $\mathrm{R}^{\mathrm{VI}}$ were most frequently observed. They showed all CLR-typical spa and sequence types and were predominantly $\mathrm{CC} 133$ or CC97 positive (Table 4).

CLF and $\boldsymbol{C L I}$. Compared with the aforementioned clusters, CLF and CLI were considerably smaller, consisting of 31 and 23 strains, respectively (Table 4). The most frequent spa type observed for CLF strains was t164 (45\%; $P<0.001)$; all the 11 remaining types contributed only 1 or 2 strains. By MLST, CLF strains were mainly attributed to ST389 $(P<0.001)$ and ST9 $(P<0.001)$; for $32 \%$ of the CLF strains, the ST was unknown (Table 4). Most of the CLF strains were associated with CC20 (55\%; $P<0.001)$ and CC9 (32\%; $P<0.001)$. Interestingly, if ST389 was observed, it was always associated with CLF (Tables 4 and 5). Except for 1 case (GTAT), the same was also true for CC20.

Considering the CLI strains, $52 \%$ were positive for t524 $(P<0.001)$, whereas for each of the 9 remaining spa types, only 1 to 2 strains were observed (Table 4 ). With 8 strains, ST71 $(P<0.001)$ was the most prominent, whereas the ST remained unknown for 7 strains. All strains could be attributed to a CC (Table 4): 11 strains were positive for CC97 $(P<0.001), 8$ for CC71 $(P<0.001), 2$ for CC8 $(P=0.190)$, and 2 for others.

CLOT. In total, $111(24 \%)$ strains were assembled in CLOT (Table 5). This cluster included all genotypes and their variants with relative frequencies below $5 \%$ and were considered rarely observed. For this cluster, a variety of spa types, ST, and CC were found (Table 5). The CLOT cluster was also characterized by a considerable number of unknown ST $(\mathrm{n}=34 ; 31 \%)$. For most of them, however, CC could be attributed.

The typing properties of the most frequent CLOT strains are outlined below. Considering GTS, all belonged to CC398 $(P<0.001)$ with sequence types ST398 $(P<0.001)$ or unknown. The most prominent spa type was t034 $(P<0.001)$. The GTZ strains were typically CC479 positive $(P<0.001)$. Furthermore, approximately half of them were positive for t2873 $(P<$ 0.001 ) and for an unknown ST (Table 5). In the case of GTAM, all except 1 were positive for $\mathrm{CC} 8(P<$
$0.001)$ and were almost exclusively positive for ST8 $(P$ $<0.001)$ and t008 $(P<0.001)$. For GTBG, all strains were exclusively positive for t543 $(P<0.001)$, ST479 $(P<0.001)$, and CC479 $(P<0.001$; Table 5$)$.

\section{Resolution of Typing Methods}

According to the companion study (Cosandey et al., 2016), RS-PCR revealed 65 different genotypes and variants integrated into 6 genotypic clusters: CLB included Staph. aureus GTB with its variants GTB ${ }^{\mathrm{I}}$, GT$\mathrm{B}^{\mathrm{II}}$, and $\mathrm{GTB}^{\mathrm{III}}$; CLC contained GTC, GTC ${ }^{\mathrm{I}}$, GTC ${ }^{\mathrm{II}}$, and $\mathrm{GTC}^{\mathrm{III}}$; CLF comprised GTF, GTF ${ }^{\mathrm{I}}$, and $\mathrm{GTF}^{\mathrm{III}}$; CLI comprised GTI and GTI ${ }^{\mathrm{I}}$ to $\mathrm{GTI}^{\mathrm{IV}}$; CLR included GTR, GTR ${ }^{\mathrm{I}}$ to $\mathrm{GTR}^{\mathrm{IV}}, \mathrm{GTR}^{\mathrm{VI}}, \mathrm{GTR}^{\mathrm{VII}}$, and $\mathrm{GTR}^{\mathrm{X}}$; and CLOT included 37 different genotypes and 4 variants. Using all genotypes and all variants, the SDI for the RS-PCR method resulted in a value of 0.9227 with a $95 \%$ CI between 0.9105 and 0.9349 . The index for spa typing (80 different spa types) was 0.9066 (95\% CI: 0.8881 to 0.9251 ). For typing based on ST (39 different ST), the SDI was 0.8738 (95\% CI: 0.8676 to 0.8900 ), whereas the diversity for CC typing (26 different CC) was 0.8720 (95\% CI: 0.8568 to 0.8872 ).

\section{Phylogeny of Animal-Origin Strains of Staph. aureus}

Phylogenetic analysis using the most parsimony approach and the 6 concatenated core adhesion genes clf $A, c l f B, f n b A$, map, sdrC, and spa generated one tree (Figure 1). A very similar tree topology was obtained when the tree was constructed using the maximum likelihood approach (data not shown). For each strain, the concatenated sequence generated 13,358 informative sites. Figure 1 demonstrates perfect association between the phylogenetic clades and the clonal complexes. The figure also shows that the human strains span the entire tree ranging from strain TCH60 to N315; the animal strains are located in between. They all evolved from human ancestors. Considering the bovine strains, 3 clades evolved from 3 different human ancestors, whereas the bovine CC8 strains (all GTB positive) evolved from a human CC8-positive ancestor. The strain M3386D, which was isolated from bovine IMI, is a special case because its concatenated sequence was fully identical to that of the human M013 strain. For the CC705 strains (cattle) and the CC130 and CC133 strains (sheep), there is a common ruminant ancestor that in turn evolved from a human ancestor. The evolutionary distances for the animal strains were considerable for the CC705 strains, moderate for the CC97, CC130, and CC133 strains, and small to minimal for the CC8, CC59, and CC5 strains. For all animal branches, the bootstrap values were $>80 \%$. 


\section{DISCUSSION}

\section{Comparison of the Typing Methods}

Strains of Staph. aureus are frequently subtyped by spa typing (Harmsen et al., 2003) or MLST (Feil et al., 2003). Both methods are based on nucleotide sequencing of 1 or 7 genes, respectively. These methods provide reproducible results, but they have a low throughput and are expensive and thus are not suitable for routine use in clinical veterinary medicine. This is particularly true for MLST, as this method requires PCR of 7 genes and sequencing of each amplicon on both strands (Feil et al., 2003). To reduce the workload and cost of the present study, novel primers for each gene (Table 2) were designed to allow single-strand sequencing. Even so, MLST requires considerable work and knowledge. In contrast, RS-PCR (Fournier et al., 2008) allows high throughput at moderate cost. For best resolution, data evaluation, and data management, a miniaturized elec-

Table 5. Distribution of spa types (t), sequence types (MLST_ST), and clonal complexes (MLST_CC) among rare genotypes of Staphylococcus aureus found in bovine milk samples in 12 European countries

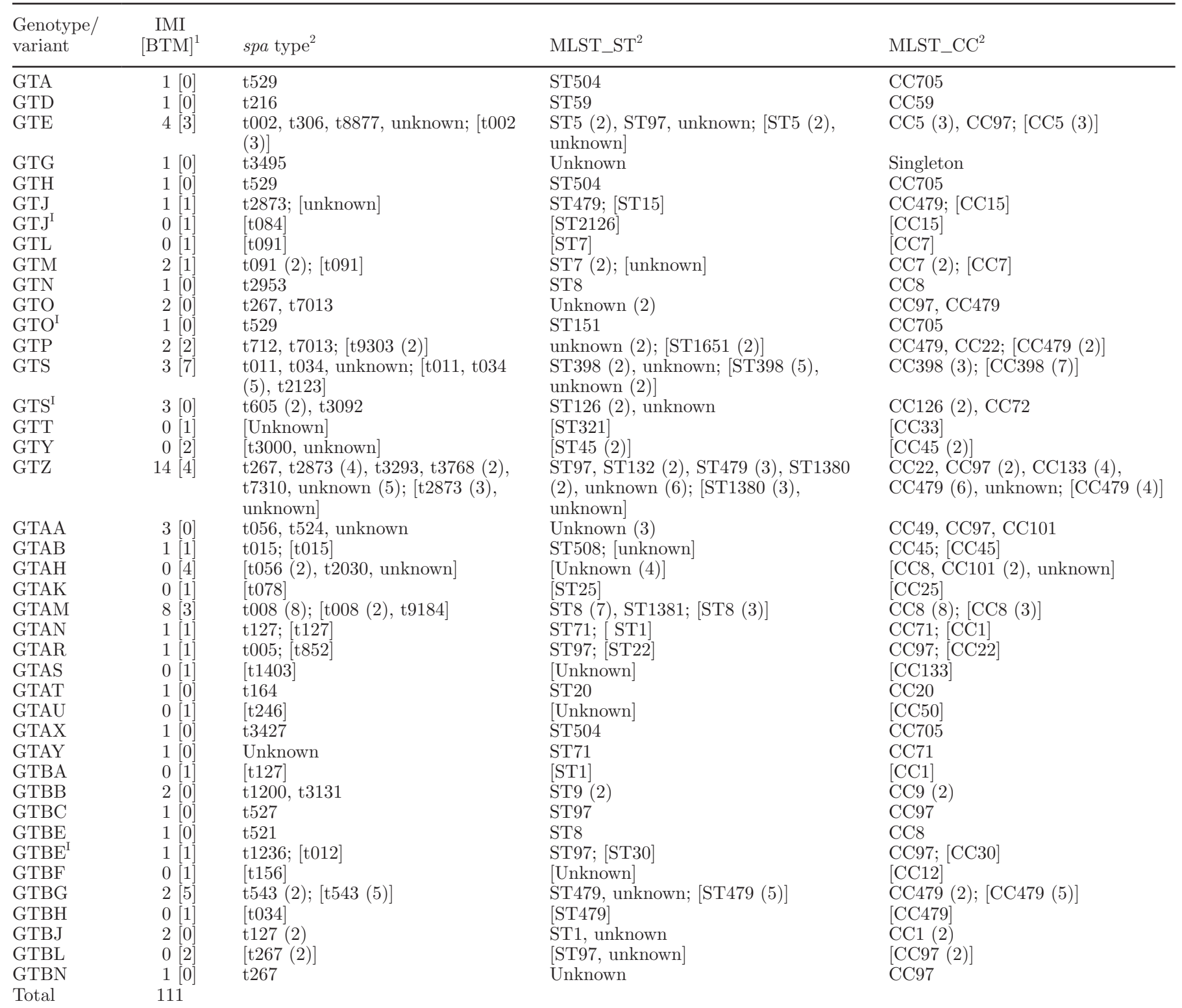

${ }^{1} \mathrm{IMI}=$ the analyzed strains were all associated with bovine subclinical IMI and had been isolated from aseptically collected milk samples or had been taken from the authors' bacterial culture collections; BTM = the isolates were obtained from bovine bulk tank milk.

${ }^{2}$ Types within brackets were observed in strains obtained from BTM. 
trophoresis system (Agilent Technologies) is preferred. Using a combination of this electrophoresis system and the software developed in-house (freely available from the authors), assignment of the pattern of bands to a genotype is standardized and straightforward. If ordinary agarose gel electrophoresis is applied, CLB and CLC strains can be discriminated from all the remaining genotypic clusters and genotypes (data not shown). This discrimination is normally sufficient for clinical use.

With an SDI of 0.9227 for bovine strains, RS-PCR showed the highest resolution followed by spa (0.9066), ST (0.8738), and CC typing (0.8720). Compared with the SDI values for spa typing (0.9802) and ST (0.9314) obtained for human strains (Pourcel et al., 2009), the corresponding values for the bovine strains were considerably lower. These results indicate that the diversity of strains involved in bovine IMI or present on dairy farms is substantially less than that of strains involved in human infections. Indeed, the 456 bovine strains used in the present study provided only 80 different spa types, whereas the 300 human strains in the study of (Pourcel et al., 2009) generated 127 spa types.

Comparison of the 3 typing methods demonstrated associations between methods, but in many cases associations were far from perfect. A high association was observed for CLB as $99 \%$ of the strains were positive for CC8 and many were positive for t2953 or t024. Nevertheless, there were also CC8-positive strains from Austria, Germany, and the Netherlands that were GTAM. Interestingly, these were almost exclusively t008-positive. Exceptionally high associations were observed for CLC, as all strains (100\%) were of spa type t529 and almost all were positive for CC705 or were singletons with an
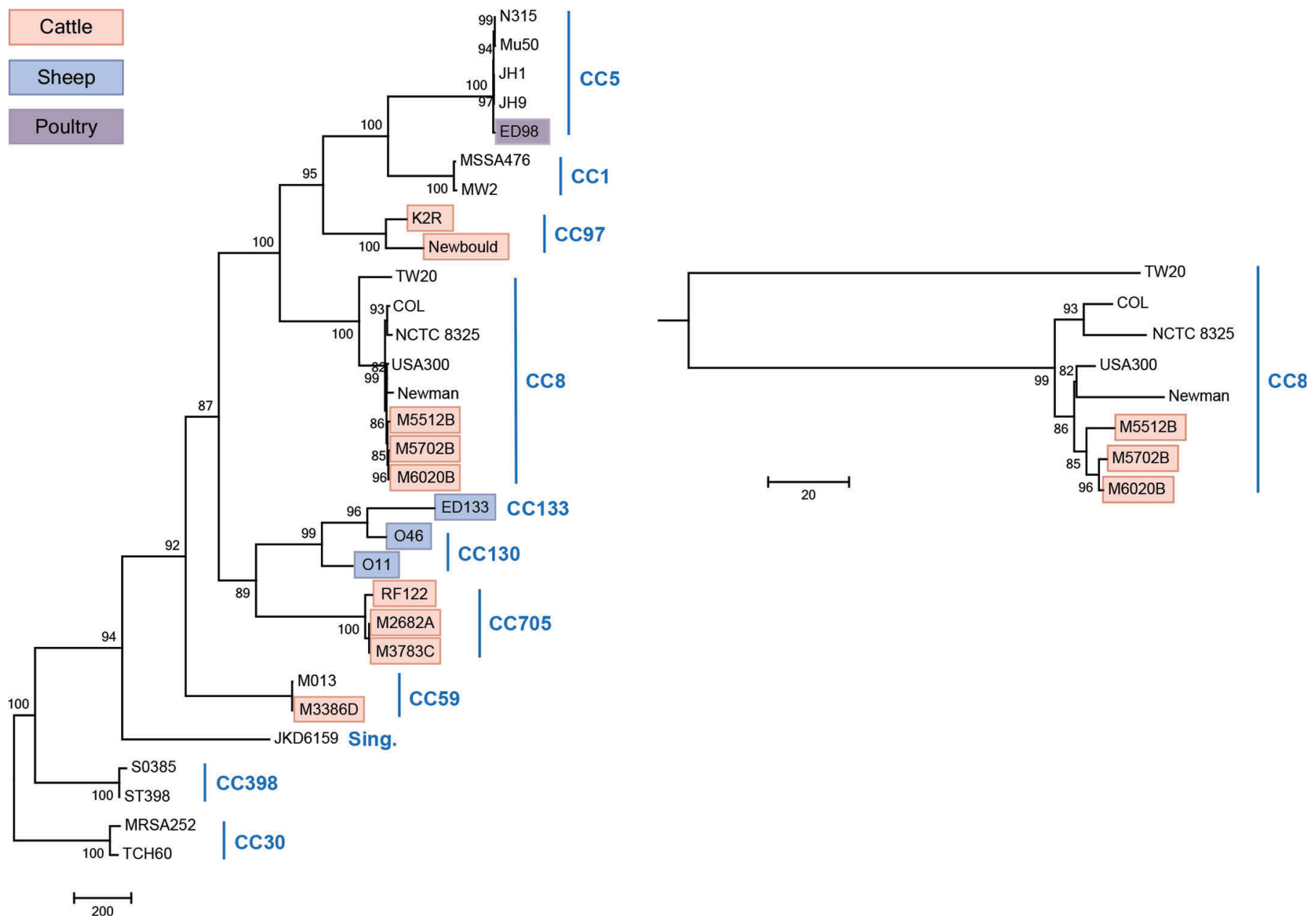

Figure 1. Phylogeny of animal strains of Staphylococcus aureus. The genes clfA, clfB, fnbA, map, sdrC, and spa of each strain were concatenated. The concatenations were then aligned and a phylogenetic tree was constructed using maximum parsimony. Colors used for shading represent the hosts from which the strains were isolated; unshaded strains represent human hosts. Strains with identical clonal complexes (CC) are marked with a straight line. Values noted left to the clades signify bootstrap values; bars indicate number of nucleotide substitutions; Sing $=$ singleton. Inset on the right: magnification of the CC8 clade. 
allelic profile closest to that of CC705. The same was true for GTS, t034, ST398, and CC398 (all), as well as for GTBG, t543, ST479, and CC479. Furthermore, significant but imperfect associations among genotypes, spa types, and CC could be demonstrated for CLF, CLI, and CLR. For these 3 genotypic clusters, however, there was extensive overlapping. Indeed, according to Table 4, each cluster included strains from 2 to 7 different CC. Clonal complex 97 was observed in all these clusters and even in CLOT (Table 5). The opposite was also true, as most of the CC observed in CLOT were also found in one or more of the major genotypic clusters (Tables 4 and 5).

The generally low association between CC and genotypic clusters is not surprising as these typing methods rely on different genetic information. For CC, assignment is based on phylogenetic information (Feil et al., 2003; Turner and Feil, 2007), whereas genotyping by RS-PCR (Fournier et al., 2008) is based on the variation of the ribosomal spacer regions (Jensen et al., 1993). If there is an association between both typing methods, it results from very high genetic conservation of the strains, as it is true for strains positive for CLB, CLC, GTS, GTAM, or GTBG.

Interestingly, we detected a significant $(P<0.001)$ and close association between the spa types and the 5 genotypic clusters (CLB, CLC, CLF, CLI, CLR). Indeed, each of the main spa types $(\mathrm{n} \geq 10)$ was associated with one predominant cluster. For example, t024 and t224 were exclusively linked to CLB and CLR, respectively (Table 4). Almost-exclusive associations were observed between t1403 and CLR, t164 and CLF, t2953 and CLB, and t529 and CLC. In contrast, CLB was associated with 11 known spa types, CLF with 12, CLI with 10, and CLR with 20 spa types. An exception was CLC, which was always linked to t529. These findings suggest that spa typing is a valuable tool for further subgrouping the genotypic clusters of bovine strains. For subgrouping CC, however, multilocus variable-number tandem-repeat analysis as performed by Pourcel et al. (2009), may be more adequate, at least for human strains. Whether these findings are also true for bovine strains needs to be evaluated, particularly as the major human CC observed in Europe (Rolo et al., 2012) are largely different from the bovine CC (Tables 4 and 5).

\section{Clonality of Bovine Strains and Phylogenetics}

Using the MLST data together with the eBURST V3 program (Feil et al., 2004), we assessed clonality of the bovine strains of Staph. aureus. The analyses demonstrated that $80 \%$ of the 281 IMI-associated strains originated from only $6 \mathrm{CC}$ (CC8, CC71, CC97, CC133,
CC479, CC705), of which CC8 $(\mathrm{n}=77), \mathrm{CC} 705$ (n $=70)$, and CC97 $(\mathrm{n}=32)$ were the largest (Tables 4 and 5). The remaining $20 \%$ of the investigated strains belonged to a large group of different CC, singletons, or unknowns. These findings demonstrate that bovine strains of Staph. aureus are clonal; this observation is not new (van den Borne et al., 2010; Sakwinska et al., 2011; Kock et al., 2013; Vandendriessche et al., 2014). A new finding of the present study, however, is that the spectrum of CC associated with bovine IMI is considerably broader than expected from the cited publications: in addition to the 6 major known CC, 20 further CC were observed. All of them were rare, however, and many of them were observed only once.

As the present study demonstrates, Staph. aureus involved in bovine IMI include a few clones, meaning that they descended from a few common ancestors. To further decipher the different CC and investigate evolution of Staph. aureus associated with cattle and other animals in more detail, phylogenetic analyses were performed as described by Kuhn et al. (2006). These analyses in the current study demonstrated that strains with identical CC always formed a single monophyletic clade (see Figure 1), meaning that MLST and the approach by Kuhn et al. (2006) reconstructed the evolution of Staph. aureus identically. This finding is amazing as both methods use different sets of genes and different phylogenetic models. The approach of Kuhn et al. (2006), however, presents the whole evolutionary process as an evolutionary tree and has a higher resolution as it decomposes one $\mathrm{CC}$ into several distinct lineages (branches).

As the present study demonstrates, there was no most recent common ancestor of the bovine or animal lineages. This nonsystematic evolutionary process also implies that each human lineage may be the ancestor of a novel bovine or animal lineage in the future. The animal lineages evolve directly from a human-associated ancestor. This is true for the animal lineages of CC5, CC8, CC59, CC97, and CC398. In the case of CC130, CC133, and CC705, however, there was one common ancestor with a tropism to ruminants from which the cattle adapted CC705 lineage evolved, whereas the CC130 lineage seems to have undergone adaptation exclusively to sheep. Interestingly, CC133 kept the tropism for cattle and sheep. This conclusion is further supported by the fact that CC130 was not observed in the present study using bovine strains. This finding, however, is in contrast to Shepheard et al. (2013), who also observed bovine strains positive for CC130. Hostspecific evolution of IMI-associated strains of Staph. aureus was also recently observed by Bar-Gal et al. (2015) confirming some results of the present study. Indeed, Bar-Gal et al. (2015) demonstrated that the goat 
and sheep strains of Staph. aureus formed one single clade that was clearly distinct from the bovine strains. In addition, the strains of the small ruminants differed from the bovine strains in their virulence gene pattern and were typically positive for CC522, a CC that has not been observed so far in cattle, including the present study.

Host switches have been described for CC5 (Lowder et al., 2009), CC97 (Smyth et al., 2009), CC130 and CC133 (Shepheard et al., 2013), CC398 (Shepheard et al., 2013), and CC705 (Guinane et al., 2010a). New in the current study is the proof that bovine $\mathrm{CC} 8$-positive lineages evolved from one most recent common ancestor with a tropism to humans. The 3 analyzed bovine strains were all Staph. aureus GTB positive but had different spa types (M5512B: t5270; M5702B: t2953; M6020B: t024), each generating a distinct lineage (significant bootstrap values in Figure 1). As a consequence, Staph. aureus GTB is the cattle-adapted CC8 clade (CC8bov) and the spa types reflect different GTB lineages, of which the t2953 and t024 lineages are by far the most prominent (Table 4).

Dates for host switches have been calculated for Staph. aureus (Lowder et al., 2009; Guinane et al., 2010a; Shepheard et al., 2013). For the CC5 clade, the human-to-poultry jump occurred approximately $38 \mathrm{yr}$ ago (Lowder et al., 2009). In the case of the CC705 clade, the switch from human to cattle dates back to about 1,500 yr ago (Guinane et al., 2010a). Based on the phylogenetic tree presented in Figure 1, the humanto-cattle jump of the CC8 clade occurred very recently. Assuming the same clock rate as for the CC5 clade, the switch is expected to have occurred about $23 \mathrm{yr}$ ago (range: 18 to $38 \mathrm{yr}$ ). For more precise dating of the bovine CC8/GTB jump, however, additional analyses are required, including historical bovine strains of Staph. aureus.

For livestock CC398 (sequenced by Schijffelen et al., 2010, and Uhlemann et al., 2012), our study demonstrated that this clade has undergone a host transition from originally humans to animals, mainly pigs and calves (van Loo et al., 2007; Lewis et al., 2008). However, as the present study demonstrates, CC398 is also a pathogen of bovine IMI. Evolution of CC398 occurred but is limited, as the corresponding branches of the tree are short. Considering CC59, the M013 (human) and the M3386D (cattle) strains formed an identical clade, meaning that both of them were of the same lineage. Indeed, all nucleotides $(\mathrm{n}=13,358)$ were identical in both isolates. The same was also true for M2682A and $\mathrm{C} 3783 \mathrm{C}$ but not for the RF122 isolate (sequenced by Guinane et al., 2010a), which differed slightly (all CC705). Interestingly, the cattle-associated lineage leading to CC705 did not further evolve in cattle until very recently, when the RF122 and the GTC/GTA lineages diverged. In addition, the CC705 clade is the only one that includes 2 genotypes, GTA and GTC. The latter is the most abundant genotype in the present study (Table 4), whereas the former is rare (Table 4); both, however, are phylogenetically very similar or even identical.

\section{Zoonotic Transfer of Staph. aureus Between Cattle and Humans}

Zoonotic transfer of pathogenic bacteria, either through direct contact or via the food chain, represents a serious threat to public health. This is particularly true for zoonotic pathogens such as Staph. aureus that may infect humans (Chroboczek et al., 2013) or that display resistance to antimicrobials used in humans (Garcia-Alvarez et al., 2011; Leverstein-van Hall et al., 2011).

The present study revealed 5 major genotypic clusters all involved in bovine IMI, of which CLB, CLC, and CLR were the most prominent. Considering CLB, all strains were CC8-positive but they included a variety of different spa types (Table 4); the most frequent one was t2953 $(\mathrm{n}=46)$. This was true even when only purely IMI-associated strains were considered (Table 4). According to the study by Grundmann et al. (2010), which mapped the geographic distribution of dominant clones causing invasive human infections in Europe, this spa type has never been observed in humans. In addition, this type is very rarely observed in the $\mathrm{Ri}-$ dom SpaServer database (http://www.spaserver.ridom. de/), in which only 7 isolates $(0.01 \%)$ are present, 2 of which were contributed by our laboratory and were isolated from milk of cows with IMI and were GTBand CC8-positive. These observations strongly suggest that the primary host of strains positive for GTB and t2953 is cattle. The situation may be different for the bovine GTB strains positive for t024. On the one hand, they belong to the cattle-adapted CC8 clade named CC8bov, but on the other hand, t024-positive strains are quite common in human infections (Grundmann et al., 2010), indicating some zoonotic potential of the bovine strains. The remaining spa types associated with GTB/CC8bov were all rarely observed in the Ridom SpaServer database $(<0.01$ to $0.03 \%)$ except for Staph. aureus t008, which is a frequent and well-known infectious pathogen in humans (Grundmann et al., 2010).

Cluster CLC was the largest cluster, including 78 IMI-associated strains. All of them were t529-positive and many were CC705-positive. In contrast to cattle, strains positive for $\mathrm{t} 529$ are very rarely observed as an infective pathogen in humans. Indeed, only one infection was found in SRL maps (www.spatialepidemiology. 
net/srl-maps), a database and map largely based on the European survey data curated by Grundmann et al. (2010). These findings strongly suggest and confirm the corresponding phylogenetic results that the primary host of strains positive for CLC/t529/CC705 is cattle. If infections occur in humans, they need to be considered as a spillover event defined as a transient infection from one host species to another that dies out without establishing transmission within the new host (Wolfe et al., 2007; Lloyd-Smith et al., 2009; Gortazar et al., 2014). The statement that CLC/t529/CC705 is primarily cattle-adapted is further supported by the fact that for the CC705 clade, the switch from human to cattle happened about 1,500 years ago (Guinane et al., 2010a), a long time for spreading and accumulating in the human population, which obviously did not occur.

Strains of CLR isolated from IMI consisted of a mixture of different spa types, of which t1403, t524, and t267 were the major ones; t524 was also the most frequent spa type observed in CLI. Types t1403 and t524 are absent in the SRL maps database, and t267 is rare. All t267-positive strains were positive for CC97, a CC that is highly associated with cattle (Rabello et al., 2007; Sakwinska et al., 2011; Vandendriessche et al., 2014) but has rarely been described as a pathogen of a human infection (Menegotto et al., 2012). In the case of t1403, most were CC133-positive and the remainder were CC97-positive. Clonal complex 133 is mainly associated with sheep and goats (Guinane et al., 2010b; Porrero et al., 2012; Smith et al., 2014), but it has also been isolated from cows with IMI (Schlotter et al., 2012; Silva et al., 2013) but not from humans. The t524 strains of CLR were almost exclusively positive for CC71, a CC that has never been described as an infectious pathogen in humans or animals. To summarize, all spa types and CC observed for CLR (and largely also for CLI) are rarely or not observed in human infections but are common in bovine IMI.

Strains of CLF are causative agents of bovine IMI (Table 4; Fournier et al., 2008) and were mainly t164 and CC20 positive. Strains positive for t164 are frequently observed in the Ridom SpaServer database (http://www.spaserver.ridom.de/), accounting for $0.18 \%$ of all isolates. They are also known to cause human infections (www.spatialepidemiology.net/srlmaps), indicating that they may infect both cattle and humans. Definite conclusions about their transfer and infectiousness in these 2 hosts are not possible; more strains and additional analyses are needed. The same is also true for the IMI-associated strains of CLOT, in particular for t002 (GTE), t008 (GTAM), and t127 (GTAN, GTBA, GTBJ), which are detected occasionally in cattle (Table 5) but frequently observed in human invasive infections. Other spa types frequently involved in human infections (Grundmann et al., 2010) such as t032, t084, t041, and t003 (listed according to their frequency) are not or only rarely (t015, t091, t012) observed in IMI-associated strains (Table 5). In general, the spa types observed in CLOT are seldom present in the Ridom database, suggesting that they are rarely involved in human disease.

\section{CONCLUSIONS}

Using bovine strains of Staph. aureus isolated from bovine IMI and BTM in 12 European countries, we demonstrated that these strains could be grouped into 6 genotypic clusters, of which CLB, CLC, and CLR were the most prominent. Of the 3 subtyping methods, RS-PCR had the highest resolution followed by spa typing and MLST. We found associations among the methods but in many cases they were unsatisfactory. Staphylococcus aureus CLB was positive for CC8 in $99 \%$ of the cases and was typically positive for t2953; it is the cattle-adapted form of CC8. Staphylococcus aureus CLC was always t529-postive and typically CC705positive. For CLR, the links among the 3 methods were poor. Bovine Staph. aureus is highly clonal and a few clones predominate. Animal strains of Staph. aureus evolve from human-adapted strains such that every human strain may be the ancestor of a novel animaladapted strain. At least in the case of the major bovine clusters CLB, CLC, CLI, and CLR, zoonotic transfer of Staph. aureus between cattle and humans seems to be very limited and different hosts are unlikely to be a source for mutual, spontaneous infections. Spillover events, however, may happen.

\section{ACKNOWLEDGMENTS}

The authors thank D. Dietrich, Swiss Group for Clinical Cancer Research, for his advice and support in statistical analysis. The study was supported by a grant of the Swiss Federal Office.

\section{REFERENCES}

Bannermann, T. L., and S. J. Peacock. 2007. Staphylococcus, Micrococcus and other catalase-positive cocci. Pages 390-454 in Manual of Clinical Microbiology. Vol. 1. P. R. Murray, ed. ASM Press, Washington, DC.

Bar-Gal, G. K., S. E. Blum, L. Hadas, R. Ehricht, S. Monecke, and G. Leitner. 2015. Host-specificity of Staphylococcus aureus causing intramammary infections in dairy animals assessed by genotyping and virulence genes. Vet. Microbiol. 176:143-154.

Bardiau, M., K. Yamazaki, J. N. Duprez, B. Taminiau, J. G. Mainil, and I. Ote. 2013. Genotypic and phenotypic characterization of methicillin-resistant Staphylococcus aureus (MRSA) isolated from milk of bovine mastitis. Lett. Appl. Microbiol. 57:181-186. 
Benson, D. A., K. Clark, I. Karsch-Mizrachi, D. J. Lipman, J. Ostell, and E. W. Sayers. 2014. GenBank. Nucleic Acids Res. 42:D32D37.

Brakstad, O. G., K. Aasbakk, and J. A. Maeland. 1992. Detection of Staphylococcus aureus by polymerase chain reaction amplification of the nuc gene. J. Clin. Microbiol. 30:1654-1660.

Chroboczek, T., S. Boisset, J. P. Rasigade, A. Tristan, M. Bes, H. Meugnier, F. Vandenesch, J. Etienne, and F. Laurent. 2013. Clonal complex 398 methicillin susceptible Staphylococcus aureus: A frequent unspecialized human pathogen with specific phenotypic and genotypic characteristics. PLoS ONE 8:e68462.

Cosandey, A., Boss, R., A., M. Luini, K. Artursswon, M. Bardiau, F. Breitenwieser, E. Hehenberger, Th. Lam, M. Mansfeld, A. Michel, G. Mösslacher, J. Naskova, S. Nelson, O. Podpečan, A. Raemy, E. Ryan, O. Salat, P. Zangerl, A. Steiner, and H. U. Graber. 2016. Staphylococcus aureus genotype B and other genotypes isolated from cow milk in European countries. J. Dairy Sci. 99:529-540. http://dx.doi.org/10.3168/jds.2015-9587.

Durbin, R., S. Eddy, A. Krogh, and G. Mitchinson. 2001. Biological sequence analysis. Pages 12-45 in Probabilistic Models of Proteins and Nucleic Acids. Reprint ed. Cambridge University Press, Cambridge, UK.

Enright, M. C., N. P. Day, C. E. Davies, S. J. Peacock, and B. G. Spratt. 2000. Multilocus sequence typing for characterization of methicillin-resistant and methicillin-susceptible clones of Staphylococcus aureus. J. Clin. Microbiol. 38:1008-1015.

Feil, E. J., J. E. Cooper, H. Grundmann, D. A. Robinson, M. C. Enright, T. Berendt, S. J. Peacock, J. M. Smith, M. Murphy, B. G. Spratt, C. E. Moore, and N. P. Day. 2003. How clonal is Staphylococcus aureus? J. Bacteriol. 185:3307-3316.

Feil, E. J., B. C. Li, D. M. Aanensen, W. P. Hanage, and B. G. Spratt. 2004. eBURST: Inferring patterns of evolutionary descent among clusters of related bacterial genotypes from multilocus sequence typing data. J. Bacteriol. 186:1518-1530.

Felsenstein, J. 2004. Bootstrap, jackknife, and permutation tests. Pages 335-363 in Inferring Phylogenies. J. Felsenstein, ed. Sinauer Associates Inc., Sunderland, MA.

Fournier, C., P. Kuhnert, J. Frey, R. Miserez, M. Kirchhofer, T. Kaufmann, A. Steiner, and H. U. Graber. 2008. Bovine Staphylococcus aureus: Association of virulence genes, genotypes and clinical outcome. Res. Vet. Sci. 85:439-448.

Garcia-Alvarez, L., M. T. Holden, H. Lindsay, C. R. Webb, D. F. Brown, M. D. Curran, E. Walpole, K. Brooks, D. J. Pickard, C. Teale, J. Parkhill, S. D. Bentley, G. F. Edwards, E. K. Girvan, A. M. Kearns, B. Pichon, R. L. Hill, A. R. Larsen, R. L. Skov, S. J. Peacock, D. J. Maskell, and M. A. Holmes. 2011. Methicillinresistant Staphylococcus aureus with a novel mecA homologue in human and bovine populations in the UK and Denmark: A descriptive study. Lancet Infect. Dis. 11:595-603.

Gortazar, C., L. A. Reperant, T. Kuiken, J. de la Fuente, M. Boadella, B. Martinez-Lopez, F. Ruiz-Fons, A. Estrada-Pena, C. Drosten, G. Medley, R. Ostfeld, T. Peterson, K. C. VerCauteren, C. Menge, M. Artois, C. Schultsz, R. Delahay, J. Serra-Cobo, R. Poulin, F. Keck, A. A. Aguirre, H. Henttonen, A. P. Dobson, S. Kutz, J. Lubroth, and A. Mysterud. 2014. Crossing the interspecies barrier: Opening the door to zoonotic pathogens. PLoS Pathog. 10:e1004129.

Graber, H. U., M. G. Casey, J. Naskova, A. Steiner, and W. Schaeren. 2007. Development of a highly sensitive and specific assay to detect Staphylococcus aureus in bovine mastitic milk. J. Dairy Sci. 90:4661-4669.

Graber, H. U., J. Naskova, E. Studer, T. Kaufmann, M. Kirchhofer, M. Brechbuhl, W. Schaeren, A. Steiner, and C. Fournier. 2009. Mastitis-related subtypes of bovine Staphylococcus aureus are characterized by different clinical properties. J. Dairy Sci. 92:1442-1451.

Grundmann, H., D. M. Aanensen, C. C. van den Wijngaard, B. G. Spratt, D. Harmsen, and A. W. Friedrich. 2010. Geographic distribution of Staphylococcus aureus causing invasive infections in Europe: A molecular-epidemiological analysis. PLoS Med. 7:e1000215.

Guinane, C. M., N. L. Ben Zakour, M. A. Tormo-Mas, L. A. Weinert, B. V. Lowder, R. A. Cartwright, D. S. Smyth, C. J. Smyth, J. A. Lindsay, K. A. Gould, A. Witney, J. Hinds, J. P. Bollback, A.
Rambaut, J. R. Penades, and J. R. Fitzgerald. 2010a. Evolutionary genomics of Staphylococcus aureus reveals insights into the origin and molecular basis of ruminant host adaptation. Genome Biol. Evol. 2:454-466.

Guinane, C. M., N. L. Ben Zakour, M. A. Tormo-Mas, L. A. Weinert, B. V. Lowder, R. A. Cartwright, D. S. Smyth, C. J. Smyth, J. A. Lindsay, K. A. Gould, A. Witney, J. Hinds, J. P. Bollback, A. Rambaut, J. R. Penades, and J. R. Fitzgerald. 2010b. Evolutionary genomics of Staphylococcus aureus reveals insights into the origin and molecular basis of ruminant host adaptation. Genome Biol. Evol. 2:454-466.

Harmsen, D., H. Claus, W. Witte, J. Rothganger, H. Claus, D. Turnwald, and U. Vogel. 2003. Typing of methicillin-resistant Staphylococcus aureus in a university hospital setting by using novel software for spa repeat determination and database management. J. Clin. Microbiol. 41:5442-5448.

Heiniger, D., B. H. van den Borne, I. Lechner, A. Tschopp, D. Strabel, A. Steiner, and H. Meier. 2014. Kosten-Nutzen-Analyse einer Intervention zur Verbesserung der Eutergesundheit in Schweizer Milchviehbetrieben. Schweiz. Arch. Tierheilkd. 156:473-481.

Hennekinne, J. A., M. L. De Buyser, and S. Dragacci. 2012. Staphylococcus aureus and its food poisoning toxins: Characterization and outbreak investigation. FEMS Microbiol. Rev. 36:815-836.

Hillis, D. M., and J. J. Bull. 1993. An empirical test of bootstrapping as a method for assessing confidence in phylogenetic analysis. Syst. Biol. 42:182-192.

Holm, S. 1979. A simple sequentially rejective multiple test procedure. Scand. J. Stat. 6:65-70.

Hummerjohann, J., J. Naskova, A. Baumgartner, and H. U. Graber. 2014. Enterotoxin-producing Staphylococcus aureus genotype B as a major contaminant in Swiss raw milk cheese. J. Dairy Sci. 97:1305-1312

Hwang, S. Y., Y. K. Park, H. C. Koo, and Y. H. Park. 2010. spa typing and enterotoxin gene profile of Staphylococcus aureus isolated from bovine raw milk in Korea. J. Vet. Sci. 11:125-131.

Jensen, M. A., J. A. Webster, and N. Straus. 1993. Rapid identification of bacteria on the basis of polymerase chain reaction-amplified ribosomal DNA spacer polymorphisms. Appl. Environ. Microbiol. 59:945-952.

Kock, R., F. Schaumburg, A. Mellmann, M. Koksal, A. Jurke, K. Becker, and A. W. Friedrich. 2013. Livestock-associated methicillin-resistant Staphylococcus aureus (MRSA) as causes of human infection and colonization in Germany. PLoS ONE 8:e55040.

Kuhn, G., P. Francioli, and D. S. Blanc. 2006. Evidence for clonal evolution among highly polymorphic genes in methicillin-resistant Staphylococcus aureus. J. Bacteriol. 188:169-178.

Leverstein-van Hall, M. A., C. M. Dierikx, S. J. Cohen, G. M. Voets, M. P. van den Munckhof, A. van Essen-Zandbergen, T. Platteel, A. C. Fluit, N. Sande-Bruinsma, J. Scharinga, M. J. Bonten, and D. J. Mevius. 2011. Dutch patients, retail chicken meat and poultry share the same ESBL genes, plasmids and strains. Clin. Microbiol. Infect. 17:873-880.

Lewis, H. C., K. Molbak, C. Reese, F. M. Aarestrup, M. Selchau, M. Sorum, and R. L. Skov. 2008. Pigs as source of methicillin-resistant Staphylococcus aureus CC398 infections in humans, Denmark. Emerg. Infect. Dis. 14:1383-1389.

Lloyd-Smith, J. O., D. George, K. M. Pepin, V. E. Pitzer, J. R. Pulliam, A. P. Dobson, P. J. Hudson, and B. T. Grenfell. 2009. Epidemic dynamics at the human-animal interface. Science 326:13621367.

Lowder, B. V.. C. M. Guinane, N. L. Ben Zakour, L. A. Weinert, A Conway-Morris, R. A. Cartwright, A. J. Simpson, A. Rambaut, U. Nubel, and J. R. Fitzgerald. 2009. Recent human-to-poultry host jump, adaptation, and pandemic spread of Staphylococcus aureus. Proc. Natl. Acad. Sci. USA 106:19545-19550.

Lundberg, A., A. Aspan, A. Nyman, H. E. Unnerstad, and K. P. Waller. 2014. Associations between bacterial genotype and outcome of bovine clinical Staphylococcus aureus mastitis. Acta Vet. Scand. 56:2.

Menegotto, F., S. Gonzalez-Cabrero, A. Cubero, W. Cuervo, M. Munoz, M. P. Gutierrez, M. Simarro, M. A. Bratos, and A. Orduna. 
2012. Clonal nature and diversity of resistance, toxins and adhesins genes of meticillin-resistant Staphylococcus aureus collected in a Spanish hospital. Infect. Genet. Evol. 12:1751-1758.

NMC (National Mastitis Council). 1999. Laboratory Handbook on Bovine Mastitis. Rev. ed. National Mastitis Council Inc., Madison, WI.

Porrero, M. C., H. Hasman, A. I. Vela, J. F. Fernandez-Garayzabal, L. Dominguez, and F. M. Aarestrup. 2012. Clonal diversity of Staphylococcus aureus originating from the small ruminants goats and sheep. Vet. Microbiol. 156:157-161.

Pourcel, C., K. Hormigos, L. Onteniente, O. Sakwinska, R. H. Deurenberg, and G. Vergnaud. 2009. Improved multiple-locus variablenumber tandem-repeat assay for Staphylococcus aureus genotyping, providing a highly informative technique together with strong phylogenetic value. J. Clin. Microbiol. 47:3121-3128.

Rabello, R. F., B. M. Moreira, R. M. Lopes, L. M. Teixeira, L. W. Riley, and A. C. Castro. 2007. Multilocus sequence typing of Staphylococcus aureus isolates recovered from cows with mastitis in Brazilian dairy herds. J. Med. Microbiol. 56:1505-1511.

Rolo, J., M. Miragaia, A. Turlej-Rogacka, J. Empel, O. Bouchami, N. A. Faria, A. Tavares, W. Hryniewicz, A. C. Fluit, and H. de Lencastre., and CONCORD Working Group. 2012. High genetic diversity among community-associated Staphylococcus aureus in Europe: results from a multicenter study. PLoS ONE 7:e34768.

Sakwinska, O., D. Morisset, J. Y. Madec, A. Waldvogel, P. Moreillon, and M. Haenni. 2011. Link between genotype and antimicrobial resistance in bovine mastitis-related Staphylococcus aureus strains, determined by comparing Swiss and French isolates from the Rhone Valley. Appl. Environ. Microbiol. 77:3428-3432.

Schijffelen, M. J., C. H. Boel, J. A. van Strijp, and A. C. Fluit. 2010. Whole genome analysis of a livestock-associated methicillin-resistant Staphylococcus aureus ST398 isolate from a case of human endocarditis. BMC Genomics 11:376.

Schlotter, K., R. Ehricht, H. Hotzel, S. Monecke, M. Pfeffer, and K. Donat. 2012. Leukocidin genes lukF-P83 and lukM are associated with Staphylococcus aureus clonal complexes 151, 479 and 133 isolated from bovine udder infections in Thuringia, Germany. Vet. Res. 43:42.

Sears, P. M., and K. K. McCarthy. 2003. Management and treatment of staphylococcal mastitis. Vet. Clin. North Am. Food Anim. Pract. 19:171-185.

Shepheard, M. A., V. M. Fleming, T. R. Connor, J. Corander, E. J. Feil, C. Fraser, and W. P. Hanage. 2013. Historical zoonoses and other changes in host tropism of Staphylococcus aureus, identified by phylogenetic analysis of a population dataset. PLoS ONE 8:e62369.

Silva, N. C., F. F. Guimaraes, M. P. Manzi, P. E. Budri, E. GomezSanz, D. Benito, H. Langoni, V. L. Rall, and C. Torres. 2013 Molecular characterization and clonal diversity of methicillin-sus- ceptible Staphylococcus aureus in milk of cows with mastitis in Brazil. J. Dairy Sci. 96:6856-6862.

Simpson, E. H. 1949. Measurement of diversity. Nature 163:688.

Smith, E. M., P. F. Needs, G. Manley, and L. E. Green. 2014. Global distribution and diversity of ovine-associated Staphylococcus aureus. Infect. Genet. Evol. 22:208-215.

Smyth, D. S., E. J. Feil, W. J. Meaney, P. J. Hartigan, T. Tollersrud, J. R. Fitzgerald, M. C. Enright, and C. J. Smyth. 2009. Molecular genetic typing reveals further insights into the diversity of animalassociated Staphylococcus aureus. J. Med. Microbiol. 58:1343-1353.

Syring, C., R. Boss, M. Reist, M. Bodmer, J. Hummerjohann, P. Gehrig, and H. U. Graber. 2012. Bovine mastitis: The diagnostic properties of a PCR-based assay to monitor the Staphylococcus aureus genotype B status of a herd, using bulk tank milk. J. Dairy Sci. 95:3674-3682.

Tamura, K., G. Stecher, D. Peterson, A. Filipski, and S. Kumar. 2013 MEGA6: Molecular Evolutionary Genetics Analysis version 6.0 Mol. Biol. Evol. 30:2725-2729.

Turner, K. M., and E. J. Feil. 2007. The secret life of the multilocus sequence type. Int. J. Antimicrob. Agents 29:129-135.

Uhlemann, A. C., S. F. Porcella, S. Trivedi, S. B. Sullivan, C. Hafer, A. D. Kennedy, K. D. Barbian, A. J. McCarthy, C. Street, D. L. Hirschberg, W. I. Lipkin, J. A. Lindsay, F. R. DeLeo, and F. D. Lowy. 2012. Identification of a highly transmissible animal-independent Staphylococcus aureus ST398 clone with distinct genomic and cell adhesion properties. MBio 3:e00027-12.

van den Borne, B. H., M. Nielen, G. van Schaik, M. B. Melchior, T. J. Lam, and R. N. Zadoks. 2010. Host adaptation of bovine Staphylococcus aureus seems associated with bacteriological cure after lactational antimicrobial treatment. J. Dairy Sci. 93:2550-2558.

van Loo, I., X. Huijsdens, E. Tiemersma, A. de Neeling, N. Sande-Bruinsma, D. Beaujean, A. Voss, and J. Kluytmans.. 2007. Emergence of methicillin-resistant Staphylococcus aureus of animal origin in humans. Emerg. Infect. Dis. 13:1834-1839.

Vandendriessche, S., W. Vanderhaeghen, J. Larsen, R. de Mendonça, M. Hallin, P. Butaye, K. Hermans, F. Haesebrouck, and O. Denis. 2014. High genetic diversity of methicillin-susceptible Staphylococcus aureus (MSSA) from humans and animals on livestock farms and presence of SCCmec remnant DNA in MSSA CC398. J. Antimicrob. Chemother. 69:355-362.

Wolfe, N. D., C. P. Dunavan, and J. Diamond. 2007. Origins of major human infectious diseases. Nature 447:279-283.

Zadoks, R., W. van Leeuwen, H. Barkema, O. Sampimon, H. Ver brugh, Y. H. Schukken, and A. van Belkum. 2000. Application of pulsed-field gel electrophoresis and binary typing as tools in veterinary clinical microbiology and molecular epidemiologic analysis of bovine and human Staphylococcus aureus isolates. J. Clin. Microbiol. 38:1931-1939. 